\title{
Technology Management of Large Industrial Enterprises
}

\author{
${ }^{1}$ Anton N. Karamyshev, ${ }^{2}$ Aleksej G. Isavnin, ${ }^{3}$ Zhanna I. Zaytseva \\ ${ }^{1-3}$ Kazan Federal University \\ Email: antonkar2005@yandex.ru
}

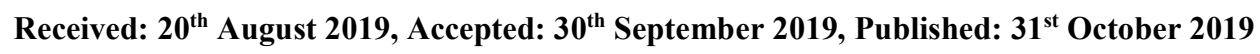

\begin{abstract}
Russian companies show significant interest in the implementation and development of process management. This is primarily due to the economic feasibility of its application. Secondly, with the opportunities that open up at each level of development of the process control system. The introduction of the process management technology of the enterprise increases in a fairly short time the efficiency of its activities and competitiveness. Surveys of respondents show that Russian enterprises have an understanding of the economic feasibility of implementing process management since the three driving factors for its implementation are the answers "increasing operational efficiency" (59\%) and "reducing costs/increasing profits" (55\%). However, a significant part of the projects for the implementation and development of process management do not achieve their goals: a third of respondents note the lack of effect from the implementation of measures to implement process management. For this reason, the identification and analysis of negative factors, as well as the search for ways to reduce their influence, are urgent tasks for industrial enterprises. This article analyzes the most significant factors that destructively affect the development of process control, and provides statistical information on these factors.
\end{abstract}

\section{Keywords}

Process Management, Industrial Enterprise, Factors, Analysis.

\section{Introduction}

The following management process problems can be distinguished:

1. Methodological problems caused by the presence of a dozen methodologies of process management, as well as the lack of a common understanding of the essence of process management and an established conceptual apparatus.

2. Problems at the stage of modeling and documenting business processes.

3. Problems of optimizing business processes.

4. Social problems that arise after the implementation of process management.

5. Problems of increasing the efficiency of the company in general based on process management.

\section{Methods}

The study applied the following methods:

1. A selective analysis of specialized literature with a high citation index for the topics indicated in the title of the article.

2. The generated array of information was systematized for the purpose of further analysis. In particular, the main problems of the implementation and development of process management were identified.

3. The analysis of the collected information is carried out, the statistical information from the ABPMP Russia report "BPM Russian Market 2015" is presented.

4. The authors interpreted the results of the study and made conclusions.

\section{Main Part}

We shall consider management process problems in details:

1. Methodological Problems Caused by the Presence of a Dozen Methodologies of Process Management, as well as the Lack of a Common Understanding of the Essence of Process Management and an Established Conceptual Apparatus.

The author's analysis revealed the following original process management methodologies: Lean Manufacturing, Six Sigma, Rummler-Branch, Hammer, SCOR, BPTrends Associates, CMMI, software methodologies of "1C", "BAAN", "SAP" [2,3]. These methodologies are used by foreign enterprises with the aim of improving the quality of the management system and gaining additional capabilities in the development and justification of management decisions. However, the research subjects of these methodologies are different, respectively, the technologies for introducing these methodologies into practice differ significantly. For example, a company that optimizes production processes and a company that modifies accounting processes in an enterprise's information system in accordance with reference models of business processes formally implement a "process approach" while performing completely different actions.

And the results obtained from the implementation of these process methodologies can be opposite: from negative (in vain resources invested in the implementation of process management, deterioration of operating results, etc.) to positive (improved enterprise manageability, increased profits, lower costs, etc.). 
Also, a large number of classifications of the concept of "business process", distinguished sets of business processes of an enterprise, attributes of business processes brings some confusion to the theoretical foundations of process management [4-8].

Only a few Russian respondents cited an increase in customer focus (31\%) and a decrease in the time it takes for new products and services to market $(21 \%)$ as driving factors for implementing process management [1], which, in our opinion, indicates that the overwhelming majority of respondents misunderstand the essence and theoretical foundations of the process approach to management (this issue was discussed in detail in $[9,10]$ ).

\section{Problems at the Stage of Modeling and Documenting Business Processes.}

At the modeling stage, the most serious are socio-economic problems. Description of business processes involves the active participation of performers of individual works and tasks. In practice, personnel often sabotage, complicate projects describing and modeling their actions. An employee can keep in secret the technology of the work in order to:

$>$ Maintain its competitive position and high status within the company's team. Description and regulation will allow for the replication of valuable experience for the benefit of the enterprise as a whole but may be contrary to the interests of specific employees.

$>$ Maintain existing payment standards and time to complete work. An analysis based on the developed process documentation can reveal significant reserves of employee time, which in most cases leads to additional workload, lower pay rates, and labor intensification.

$>$ Preservation of existing jobs in the enterprise. Modeling, description, and subsequent automation of business processes lead to a reduction in the need for labor resources and subsequent staff reductions. Understanding this significantly demotivates the staff when implementing process management.

The results of the polls indicate that one of the main constraining factors for introducing the process approach is the inertia of employees [1].

The forms of sabotage of the process management implementation project can be different: from refusing to work with business process description groups under various pretexts (for example, high workload, urgent other projects, lack of time, etc.) to issuing incomplete information, hiding important work nuances, psychological pressure on business analysts, etc., which can lead to the formation of work models that do not reflect reality, complicates their analysis, discredits the idea of a process approach to management.

Thus, it is important to develop a set of measures to protect the interests of employees and to train employees to take notes of modeling business processes in order to partially delegate them the authority to describe the work. However, practical issues are of little importance to training issues: two-thirds of Russian respondents noted that process management training is not held at their enterprises [1].

In addition, $37 \%$ of respondents noted the lack of interest of the management in the implementation of the process approach [1]. As practice shows, if managers and employees who perform them are not involved in the process of reorganizing processes, then such work is $80-90 \%$ weirded into failure [11].

\section{Problems of Optimizing Business Processes.}

Problems of optimizing the cost, duration, and complexity of business processes arise after their modeling. Optimization of the described business processes is currently, in many ways, a creative process. Its effective optimization requires attracting specialists in the subject field of interest in order to discuss and develop a set of optimization measures. At the same time, it is necessary to find the points of application of efforts giving the greatest economic effect that will improve the overall performance of the enterprise. Methodologically, these issues have not yet been worked out properly to the application level.

In our opinion, economic and mathematical methods (linear and dynamic programming, network management, game theory, queuing systems, inventory management and others [12]) have a high potential for optimizing business processes but they need to be further developed subject to the specifics of the process management and features of large engineering enterprises.

4. Social Problems that arise after the Implementation of Process Management.

Automation of business processes and increased efficiency in the use of labor resources lead to an excess of labor in the enterprise. The problem is solved by retraining staff for new promising areas for the company or its reduction.

\section{Problems of Increasing the Efficiency of the Company in General Based on Process Management.}

Any measures to increase the efficiency of activities require investment in new technologies, staff training, and the development of new projects. The invested resources must pay off within a reasonable period of time, in order to make a management decision, in most cases, they develop a business plan for the investment project.

It should be noted that projects to improve business processes are considered, as a rule, at the local level, i.e. the impact of the management decision on related business processes and the business process network as a whole is not evaluated. There is also a methodological problem of the justified management of the enterprise as a system based on business processes, which negatively affects its performance indicators.

\section{Results and Discussion}

The conducted analysis identified five groups of problems:

1. Methodological problems caused by the presence of a dozen methodologies of process management, as well as the lack of a common understanding of the essence of process management and an established conceptual apparatus. 
2. Problems at the stage of modeling and documenting business processes.

3. Problems of optimizing business processes.

4. Social problems that arise after the implementation of process management.

5. Problems of increasing the efficiency of the company in general based on process management.

Each of them has its own specific features and requires individual approaches to the solution.

\section{Summary}

We consider methodological problems of the implementation and development of process management to be the most significant. The earlier analysis of process management methodologies, in our opinion, actualized the need to formulate a process management methodology for an enterprise as a system.

The new methodology should

a) Assess the impact of local management decisions on the system of business processes, the effectiveness of the enterprise as a whole, the cost of production;

b) Form the basis for improving the quality of management decisions;

c) Systematically determine the points of application of effort in order to improve the performance of the enterprise, to develop and implement the necessary organizational and technical measures.

Also, a modified management system based on this methodology should operate with cost values at each stage of the technological cycle or that ensure the main production of business processes. For this purpose, it is necessary to improve existing methods for calculating the cost of production in the context of the main and auxiliary business processes, as well as considering the specifics of large industrial enterprises:

1) Large and complex core business processes;

2) Large and complex auxiliary (providing) business processes;

3) A large number of primary and auxiliary business processes;

4) A complex and large-scale intraorganizational turnover, causing a large number of relationships between business processes;

5) The complex cyclical nature of economic relations between auxiliary business processes;

6) A wide range of products;

7) A wide range of resources consumed by the main and auxiliary business processes;

8) Limited flexibility (in the short term) of the modification of the main and part of the auxiliary business processes.

\section{Conclusions}

All these problems of implementing process management have a social aspect: they are associated either with groups implementing the process approach, or with company personnel, or with analysts optimizing the company's business. A critical factor in the successful implementation and development of process management implementation projects is their support from the company's team and management. Also, a modern socially-oriented economy and the development of civil society increases the importance of the issues of forming the image and reputation of corporations. For these reasons, company management should pay considerable attention to social factors in the implementation of process management. The growth of labor productivity and the automation of business processes arising from the successful implementation of process management projects lead to the release of a large number of employees, optimization of the number of employees and part-time employment at the enterprise.

\section{Acknowledgments}

The work is performed according to the Russian Government Program of Competitive Growth of Kazan Federal University.

\section{References}

[1] Koptelov A., Filatova M. ABPMP Russia Research “The Russian BPM Market 2015” [Electronic resource]. URL: http://abpmp.org.ru/ (accessed date 30.03.2017).

[2] Harmon, P. A BPTrends Report «The State of Business Process Management-2016» [Electronic resource]. URL: www.bptrends.com (accessed date: 30.03.2017).

[3] Karamyshev A.N. Comparative analysis of process-based management methodologies // Turkish Online Journal Of Design Art And Communication. - 2017.- Vol.7, Is.. - P.1693-1699.

[4] Karamyshev A., Makhmutov I., Utyaganov R. Problems of Institutionalization of the Process-Based Management in Industrial Enterprises // International Business Management. 2015. № 9(6). P.1576-1579.

[5] Ishmuradova I.I., Sibaeva G.R. Digital transformation of business processes as a process of organizational changes of an enterprise in an innovative economy // Science of Krasnoyarsk. 2016. No. 6-2 (29). P. 92-97.

[6] Amirkhanov K.G. Business processes of an industrial enterprise: concept and classification // Innovations in the industrial complex. 2005. P. 140-149.

[7] Rubtsov S.V. Clarification of the concept of a business process // Management in Russia and abroad. 2001. No. 6. 
[8] Udalov F.E., Kuznetsov V.P., Garina E.P. Studying the methods of process management of an industrial enterprise // Bulletin of N.I. Lobachevsky Nizhny Novgorod University. 2011. №5 (2). P. 232-237. URL: https://cyberleninka.ru/article/v/izuchenie-metodov-protsessnogo-upravleniya-promyshlennym-predpriyatiem

[9] Karamyshev A.N. Analysis of the essence of the process approach to enterprise management // Kompetentsiia. 2017. No. 5. P. 47-51.

[10] Karamyshev A.N. Analysis of Existing Approaches to Management of Industrial Enterprises // HELIX. - 2018. Vol.8, Is.1. - P.2893-2897.

[11] Repin V.V., Eliferov V.G. Process approach to management. Modeling of business processes, Moscow: "Standards and Quality", 2008, 408 p.

[12] Kremer N.Sh., Putko B.A., Trishin I.M., Fridman M.N. Studying the operations in Economics: a study guide for universities. M.: UNITY. 2005. 407 p. 